REVESCO. Revista de Estudios Cooperativos ISSN: $1885-8031$

http://dx.doi.org/10.5209/REVE.63563

\title{
La asociación cooperativa como factor de sostenibilidad del sistema cafetalero en comunidades marginadas
}

\author{
Victoria Pacheco Almaraz ${ }^{1}$, María Isabel Palacios Rangel ${ }^{2}$, Fernando Cervantes Escoto ${ }^{3}$, \\ Jorge Ocampo Ledesma ${ }^{4}$ y Jorge Aguilar Ávila ${ }^{5}$
}

Recibido: 11 de junio de 2018 / Aceptado: 4 de febrero de 2019

Resumen. En la actualidad, los modelos de desarrollo socioeconómicos sostenibles han sido estudiados con significativa importancia dada la crisis multidimensional presente, por ello en esta contribución, se analiza el sistema de producción cafetalero de una zona marginada con grupos de productores asociados y no, mediante un ejercicio de comparación a través de ocho indicadores derivados de los atributos generales de sostenibilidad que consideran los ejes social, económico y ambiental, con el objetivo de ubicar los factores determinantes de la misma y evidenciar la importancia que tienen las sociedades cooperativas como medio para contribuir al desarrollo sostenible. Este artículo se basó en trabajo de campo que recogió información tanto cuantitativa como cualitativa de los productores y su sistema productivo con la cual se ha diseñado un índice que permite identificar los niveles de sostenibilidad del sistema de producción. Se obtuvo que los asociados presentan un Índice de Sostenibilidad (IS) mayor, con factores explicativos que residen en el sobreprecio (eje económico), acceso a innovaciones y capacitaciones constantes (eje social). La brecha existente entre los valores máximo y mínimo del IS de los productores, fue elevado con lo que se demuestra que existen productores cuya forma de producir es sostenible y otros que no lo logran. En los resultados se destaca el potencial que tienen las cooperativas cafetaleras como agentes de transformación socioeconómica en los territorios rurales con limitaciones de diversa índole y se concluye que existe relación entre la asociación y la sostenibilidad, es decir, las cooperativas locales abren expectativa de éxito y contribuyen al fortalecimiento del sector cafetalero.

Palabras clave: MESMIS; UPIZS SUR; CEPCO; Índice de sostenibilidad; Productores organizados. Claves Econlit: P13; Q01; Q13.

1 Universidad Autónoma Chapingo, CIESTAAM

Dirección de correo electrónico: vpacheco@ ciestaam.edu.mx

2 Universidad Autónoma Chapingo, CIESTAAM

Dirección de correo electrónico: marisapalacios@gmail.com

3 Universidad Autónoma Chapingo, CIESTAAM

Dirección de correo electrónico: tartalian04@gmail.com

4 Universidad Autónoma Chapingo, CIESTAAM

Dirección de correo electrónico: ocampo@ciestaam.edu.mx

5 Universidad Autónoma Chapingo, CIESTAAM

Dirección de correo electrónico: jaguilar@ ciestaam.edu.mx 
[en] The cooperative association as a factor of sustainability of the coffee system in marginalized communities

\begin{abstract}
Currently, the models of sustainable socioeconomic development have been studied with significant importance given the present multidimensional crisis, therefore in this contribution, the coffee production system of a marginalized area is analyzed with groups of associated producers and not, through an exercise of comparison through eight indicators derived from the general attributes of sustainability that consider the social, economic and environmental axes, with the objective of locating the determining factors of it and evidencing the importance of cooperative societies as a means to contribute to the development sustainable. This article was based on fieldwork that gathered both quantitative and qualitative information from producers and their production system with which an index was designed to identify the levels of sustainability of the production system. It was obtained that the associates present a higher Sustainability Index (SI), with explanatory factors that reside in the overpricing (economic axis), access to innovations and constant training (social axis). The gap between the maximum and minimum values of the IS of the producers was high, which shows that there are producers whose production is sustainable and others who do not. The results highlight the potential of coffee cooperatives as agents of socio-economic transformation in rural territories with different types of constraints, and it is concluded that there is a relationship between association and sustainability, that is, local cooperatives open the expectation of success and they contribute to the strengthening of the coffee sector.
\end{abstract}

Keywords: MESMIS; UPIZS SUR; CEPCO; Sustainability index; Organized producers.

Sumario. 1. Introducción. 2. Marco teórico y conceptual. 3. Metodología. 4. Resultados y discusión. 5. Conclusiones. 6. Referencias bibliográficas.

Cómo citar: Pacheco, V., Palacios, M.I., Cervantes, F., Ocampo, J. y Aguilar, J. (2019) La asociación cooperativa como factor de sostenibilidad del sistema cafetalero en comunidades marginadas. REVESCO. Revista de Estudios Cooperativos, Segundo Cuatrimestre, No 131, pp. 125-150. DOI: 10.5209/REVE.63563.

\title{
1. Introducción
}

En la actualidad diversas empresas han cambiado su percepción respecto al rol que deben desempeñar según su entorno, como consecuencia de factores de diversa índole como privatización de economías, globalización de mercados, nuevas tecnologías de información, modificación de pautas de la demanda, entre otros señalados por Nieto y Fernández (2004). Por ello, cobra relevancia su actuar responsable y los impactos sociales y medioambientales de sus acciones.

En ese sentido, se puede hablar de procesos de desarrollo económico y expansión de mecanismos de desarrollo social, orientados al desarrollo sostenible a través de las cooperativas, donde los principios de ética y responsabilidad son determinantes (Todaro, 2006). El informe Brundtland (1987), define este desarrollo como la satisfacción de las necesidades de las generaciones presentes sin comprometer las posibilidades de las futuras para atender las suyas. Bajo este contexto, las cooperativas cafetaleras juegan un papel importante en el alcance de la meta, a través de la participación responsable de los asociados en sus diversos procesos internos.

Por otra parte, el estudio del café es relevante por ser un cultivo que en el escenario mundial presenta particularidades muy marcadas, como su concentración productiva en países que poseen climas tropicales, incluyendo México, donde tiene 
importancia social y económica al integrar un universo de productores de pequeña y mediana escala productiva, con tres millones de familias y diecisiete etnias (AMECAFE, 2012); además, consolida vínculos entre espacios locales y globales (comunidades cafeticultoras, mercados convencionales y especializados).

Entre las entidades productoras se encuentra Oaxaca, asentada al sur del país, que ocupa el cuarto lugar en la producción, con una repercusión económica, territorial y social en la vida cotidiana de 100 mil familias (SAGARPA, 2011). Cabe señalar que en este sector, si bien el sistema de comercialización vía intermediarios subsiste, las organizaciones cafetaleras cumplen un papel fundamental en la inserción de los pequeños productores en el mercado por medio de las redes de valor, como señalan Lele (1981); Rondot y Collion (2001); Ramírez et al. (2006); y Remy y Glave (2007).

Según Bartra (2006), el sector cafetalero mexicano se encuentra en una espiral de deterioro con severos impactos que afectan su sostenibilidad y generan una situación desfavorable que reduce a nivel de sobrevivencia a los pequeños cafeticultores; y quienes han paleado la situación de mejor manera son los asociados a empresas sociales que acopian y benefician grandes cantidades del aromático, accediendo a nichos de mercado que pagan sobreprecio, factor que a largo plazo contribuye a mejorar los parámetros de sostenibilidad del sistema territorial que le da contexto a la producción.

En ese sentido, Ostrom (2004), explica en parte este fenómeno, al referenciar procesos asociativos que conducen a la acción colectiva, presentada cuando más de una persona une esfuerzos para lograr un resultado social. Paradójicamente, este proceso y sus beneficios solo se visibilizan de forma tangencial en México, según estadísticas oficiales que indican que el número de productores efectivamente asociados para realizar actividades productivas y comerciales, no rebasa el $10 \%$ del total en el ámbito nacional (SAGARPA-FAO, 2006).

En torno a esto último, existen diversas explicaciones que vinculan su origen con estrategias gubernamentales de control político del sector campesino, mediante la presencia del Estado, que excluyó y desprestigió durante décadas, toda posibilidad de asociación fuera de este sistema. En ese escenario, la conformación de asociaciones independientes de productores agrícolas surgió como un elemento disruptivo de esta situación y la trastocó (Rubio, 1996).

Todos estos elementos, ponen en tela de juicio el impacto real que tienen las asociaciones gremiales, representativas del sector agropecuario mexicano, y generan dudas acerca de la sostenibilidad del sistema de producción de los asociados a cooperativas. De ahí, que ubicar los factores determinantes de la sostenibilidad del sistema cafetalero, sea una cuestión importante a responder. Por lo tanto, el objetivo de esta contribución es analizar los factores de sostenibilidad que presenta el escenario de los asociados y no asociados cooperativos, a partir de la consideración de tres dimensiones analíticas (económica, social y ambiental), donde el primer escenario corresponde al sistema de socios de la Unión de Productores Indígenas Zapotecos de la Sierra Sur, Sociedad Cooperativa de Responsabilidad Ilimitada (UPIZS-SUR S. C. de R.I), y el otro al practicado por cafeticultores no asociados a la misma.

Para cumplir con el objetivo de este trabajo se identifica, caracteriza y monitorean puntos críticos de los sistemas para lo cual se utilizó como enfoque 
metodológico el Marco para la Evaluación de Sistemas de Manejo de Recursos Naturales incorporando Indicadores de Sostenibilidad (MESMIS) desarrollado por Masera, Astier y López-Ridaura (2000), con adaptaciones propias considerando el Índice de Adopción de Innovaciones (INAI) propuesto por Muñoz, Aguilar, Rendón, y Altamirano (2007), a partir de los cuales se creó un Índice de Sostenibilidad (IS). La hipótesis de la que se parte es que el sistema productivo de los asociados presenta mayores niveles de sostenibilidad, debido a la conformación de atributos que adquieren en su covinculacion con la UPIZS SUR, reflejado en mayores rendimientos y precios, mayor escala de producción, así mismo, un índice manejable de diversidad de especies arbóreas y un ritmo sostenido de participación social.

Para lo anterior, y tras esta introducción, se plantea la metodología utilizada, el trabajo realizado, así como resultados obtenidos, y la confrontación de éstos con otros estudios. Por último, se adjuntan las conclusiones y la bibliografía referenciada.

\section{Marco teórico y conceptual}

De acuerdo con la definición de la Alianza Cooperativa Internacional (ACI, 2014), una organización es una "asociación autónoma de personas, unidas en forma voluntaria para satisfacer necesidades en común, mediante una empresa de propiedad conjunta y gestión democrática". Por su parte, Gottret, Junkin, e Ilabaca (2011), mencionan que es un proceso de agrupación de personas que trabajan de forma coordinada y concertada para lograr una visión, metas y objetivos comunes, los cuales son definidos de manera colectiva. Este autor señala que la organización les permite a las personas alcanzar metas y objetivos que de forma individual no serían posibles o que tomaría más tiempo conseguir, así como hacer un uso más efectivo de los recursos con que cuentan.

Lo anterior, recae en la llamada acción colectiva, que de acuerdo con Muñoz, Santoyo y Flores (2010), debe tener como fin, la creación de organizaciones en forma de empresas que contribuyan al mejoramiento de las condiciones de vida de la población rural, en un espacio territorial determinado a través de la generación de empleos e ingresos y otro tipo de satisfactores y que de acuerdo con Ostrom (2004) ocurre cuando se requiere que más de una persona contribuya con un esfuerzo para lograr un resultado. Mientras que Olson (1992), señala que se produce cuando, además de la esperanza de alcanzar el objetivo compartido, existe un mecanismo que incentiva la participación en la acción en la forma de beneficios selectivos, privados, para quienes lo hagan.

En ese sentido, el cooperativismo es una de las formas de organización predominante en el medio rural, y a través de ella los productores buscan asociarse para proveerse de una gama de servicios, resaltando la obtención de sobreprecios, mejores precios de insumos y certidumbre para la comercialización de su producción, fomentando la solidaridad, participación y corresponsabilidad.

En relación al desarrollo sostenible, de acuerdo con Sachs (1981), fue a lo largo de la segunda mitad del siglo XX, cuando las inquietudes sobre el medio ambiente y las teorías de desarrollo empezaron a correlacionarse, dando lugar al concepto de 
ecodesarrollo que define como un desarrollo socialmente deseable, económicamente viable y ambientalmente prudente. De acuerdo con este autor, este concepto desencadenó el surgimiento del concepto de desarrollo sostenible acuñado en la Conferencia de Naciones Unidas sobre Medio Ambiente Humano en Estocolmo en 1972, donde se perfilaron directrices sobre su implementación, pero no fue hasta 1987 cuando fue definido e incorporado de forma operativa en el Informe de la Comisión Mundial sobre Medio Ambiente y Desarrollo.

Tras la aparición del Informe Nuestro Futuro Común (1987-1988), se entendió que su objetivo es satisfacer necesidades actuales sin comprometer la capacidad de las generaciones futuras para satisfacer las suyas (Naredo, 1996). De este modo, analizando la trayectoria del concepto, se observa que no cuenta con una definición única, ya que ha sufrido de continuos vaivenes entre posturas desarrollistas y ambientalistas, aunque haya un claro consenso, en que la sostenibilidad viene de la mano de tres componentes (social, económico y ambiental).

La ambigüedad del término se puede explicar por la imprecisión en su definición e imposibilidad de su medición que se refleja a través de diversos enfoques metodológicos, y al respecto, en este trabajo se recomienda hacer uso de indicadores económicos, sociales y ambientales con un enfoque multicriterio, adaptando para cada circunstancia o zona los indicadores. De un mismo modo, su ponderación dependerá del sistema en el que se trabaje y se concluye que no existe una definición única de sostenibilidad, debe definirse localmente y atendiendo a la diversidad ambiental y sociocultural, pero sin perder la perspectiva global que ayuda a planificar a distintas escalas y a considerar valores universales.

\section{Metodología}

\section{1. Área de estudio y unidad de análisis}

El estudio se realizó en el municipio de San Agustín Loxicha, perteneciente al Distrito de Pochutla, en el estado de Oaxaca. Esta entidad municipal comprende setenta y cuatro comunidades con índice de marginación muy alto (CONAPO, 2010) y se sitúa a $1.820^{6} \mathrm{msnm}$ favoreciendo cultivos de altura como el café (Figura 1), con recopilación de información en el periodo de diciembre de 2015 y septiembre de 2016.

6 Uso de Escritura numérica con estilo Europeo en todo el material. 
Figura. 1. Ubicación de la zona de estudio (San Agustín Loxicha, Pochutla, Oaxaca).

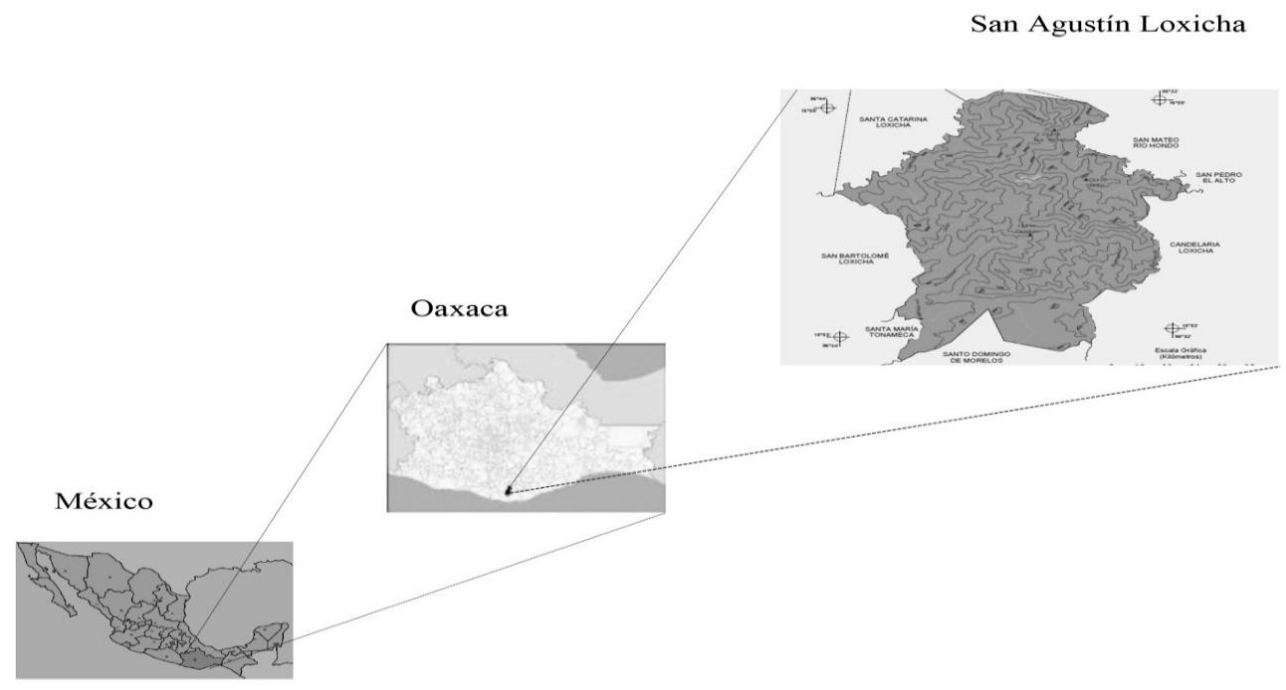

Fuente: Elaboración propia con base en INEGI (2012)

La unidad de análisis la constituyen pequeños cafetaleros dedicados a su cultivo y comercialización; se añade que la UPIZS-SUR trabaja de forma conjunta con la Coordinadora Estatal de Productores de Café de Oaxaca (CEPCO), como asociación matricial extendida en casi todas las regiones de la entidad, ambas fundadas con el objetivo de erradicar la intermediación de pequeños acopiadores en las zonas cafetaleras.

\subsection{Fuentes, colecta y análisis de la información}

Para determinar el número de productores no asociados y localidades a estudiar, al carecer de información relacionada a dichos productores y al sistema productivo, se utilizó el total de localidades que constituyen el municipio, definiéndose siete, con muestreo estratificado simple a partir del "número de habitantes" dentro de los cuales se ubicaron ochenta y siete productores no asociados, que se localizaron con el padrón del programa gubernamental "PROCAFÉ e impulso productivo al café7" del año 2011 y a los cuales se procedió a encuestar personalmente al igual que a los asociados (Ver Tabla 1 para resumen de procedimiento).

7 Reglas de operación del Programa PROCAFÉ e impulso productivo al café. Diario Oficial de la Federación,

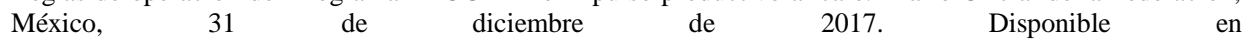
http://www.dof.gob.mx/nota detalle popup.php?codigo=5483277. 
Tabla. 1. Resumen de muestreo para productores no asociados en la cooperativa.

\begin{tabular}{|c|c|c|c|}
\hline Localidades & $\begin{array}{l}\text { Habitantes } \\
\text { (Total) }\end{array}$ & $\begin{array}{l}\text { Productores } \\
\text { (Total) }\end{array}$ & Fuentes \\
\hline 74 & 22.549 & 1.087 & 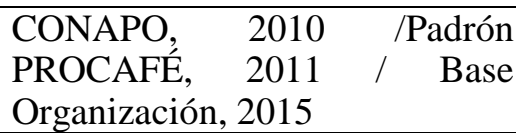 \\
\hline \multicolumn{4}{|c|}{ Primer filtro: muestreo estratificado en función del número de habitantes } \\
\hline $\begin{array}{l}\text { Localidades } \\
7\end{array}$ & $\begin{array}{l}\text { Habitantes } \\
2.063\end{array}$ & $\begin{array}{l}\text { Productores } \\
87\end{array}$ & $\begin{array}{l}\text { Fuentes } \\
\text { CONAPO, 2010 / Padrón } \\
\text { PROCAFÉ, 2011 / } \\
\text { Organización, 2015 }\end{array}$ \\
\hline
\end{tabular}

Fuente: Elaboración propia con base en muestreo estadístico, 2015.

En el caso de los asociados, también, se utilizó muestreo estratificado, con datos técnicos obtenidos del registro de la organización, en este caso mediante la variable "superficie cultivada con café", con un $95 \%$ de confianza y $10 \%$ de precisión, obteniendo una muestra de veintidós productores, más $20 \%$ de posibles "no respuestas", es decir, cuatro personas más (Tabla 2).

Tabla. 2. Resumen de muestreo para productores asociados.

\begin{tabular}{lcrrr}
\hline Estrato & $\begin{array}{c}\text { Criterio } \\
\text { (Superficie) }\end{array}$ & $\begin{array}{r}\text { Número de } \\
\text { Productores }\end{array}$ & $\begin{array}{r}\text { Proporción } \\
(\boldsymbol{\%})\end{array}$ & $\begin{array}{r}\text { Tamaño de } \\
\text { muestra }\end{array}$ \\
\hline I & Menos de 2 ha & 108 & 48,6 & 6 \\
II & De 2,1 a 4,5 ha & 73 & 32,9 & 14 \\
III & Más de 4,5 ha & 41 & 18,5 & 6 \\
Total & & 222 & 100,0 & $\mathbf{2 6}$ \\
\hline
\end{tabular}

Fuente: Elaboración propia con base en datos de UPIZS SUR, 2015.

Respecto al instrumento de colecta de información, en el caso de los no asociados en la cooperativa, estuvo conformado por cuatro secciones, mientras que para los asociados fue de cinco: datos generales, caracterización de la unidad productiva, perfil del productor, perspectivas del sistema según condición (asociado y no asociado), liderazgo (para socios que han desempeñado cargos en la organización). Se destaca que el enfoque metodológico empleado para el análisis correspondió al MESMIS, debido a que dentro de las evaluaciones de sostenibilidad es la de mejor ajuste a los objetivos perseguidos y circunstancias presentes, además, se basa en una relación equilibrada entre la sociedad y la naturaleza con retroalimentación entre los actores del sistema de producción y 
facilita el análisis mixto de la información (cualitativo / cuantitativo), a partir de los atributos e indicadores que contempla.

Posteriormente, se procedió a medir y monitorear atributos mediante la utilización de criterios de diagnóstico e indicadores vinculados a tres dimensiones de sostenibilidad (Tabla 3).

Tabla. 3. Indicadores de sostenibilidad en la producción de café en San Agustín Loxicha,

Oaxaca.

\begin{tabular}{|c|c|c|c|}
\hline Atributo & $\begin{array}{l}\text { Criterios de } \\
\text { diagnóstico }\end{array}$ & Indicador & Dimensión $^{* *}$ \\
\hline \multirow[t]{3}{*}{ 1. Productividad } & $\begin{array}{l}\text { Rendimiento y } \\
\text { calidad }\end{array}$ & Rendimiento & A \\
\hline & Rentabilidad & $\begin{array}{l}\text { Demanda de fuerza de } \\
\text { trabajo }\end{array}$ & $\mathrm{E}$ \\
\hline & & Densidad de plantación & A \\
\hline \multirow[t]{7}{*}{$\begin{array}{l}\text { 2. Estabilidad, } \\
\text { resiliencia y } \\
\text { confiabilidad. }\end{array}$} & $\begin{array}{l}\text { Diversidad } \\
\text { biológica }\end{array}$ & $\begin{array}{l}\text { Número de especies } \\
\text { manejadas y árboles } \\
\text { sombra }\end{array}$ & A \\
\hline & Vulnerabilidad & Precio del café & $\mathrm{E}$ \\
\hline & económica & Disponibilidad de & $\begin{array}{l}\mathrm{E} \\
\mathrm{F}\end{array}$ \\
\hline & & $\begin{array}{l}\text { Diversificación de } \\
\text { mercados* }\end{array}$ & \\
\hline & $\begin{array}{l}\text { Diversidad } \\
\text { económica }\end{array}$ & $\begin{array}{l}\text { Ingreso por otras } \\
\text { especies }\end{array}$ & $\mathrm{E}$ \\
\hline & $\begin{array}{l}\text { Vulnerabilidad } \\
\text { biológica }\end{array}$ & Incidencia de plagas & A \\
\hline & $\begin{array}{l}\text { Vulnerabilidad } \\
\text { social }\end{array}$ & $\begin{array}{l}\text { Permanencia de los } \\
\text { productores en el } \\
\text { sistema* }\end{array}$ & S \\
\hline \multirow[t]{3}{*}{ 3. Adaptabilidad } & Capacidad de & Productores por sistema* & S \\
\hline & cambio & Acceso a innovaciones & $\mathrm{S}$ \\
\hline & & Superficie por sistema & $S$ \\
\hline 4. Equidad & Participación social & $\begin{array}{l}\text { Mecanismos de toma de } \\
\text { decisiones* }\end{array}$ & S \\
\hline \multirow[t]{3}{*}{ 5. Autogestión } & Participación & Participación social ${ }^{*}$ & $S$ \\
\hline & Productores & Productores capacitados & S \\
\hline & Control & $\begin{array}{l}\text { Control social del } \\
\text { proceso* }\end{array}$ & S \\
\hline
\end{tabular}

${ }^{* * *}$ Dimensiones: A (ambiental), E (económica) y S (social). Nota: Superíndices ( ${ }^{*}$ ) señalan variables no desarrolladas en la presente debido a su análisis en otra contribución con carácter cualitativo. Fuente: Elaboración propia con base en Masera et al. (2000). 
Es importante destacar que la cantidad de sombra en los cafetales puede tener efectos negativos sobre ellos, por ello, es común su regulación a través del uso de árboles sombra (AS), que modificando el ambiente dentro del cafetal refrescando el aire y aumentado su humedad, además, producen residuos orgánicos que contribuyen en la fertilidad del suelo y pueden representar una fuente de ingresos adicionales, de ahí su consideración en el estudio. Por otra parte, se destaca que debido a que los indicadores anteriores condensan información de tipo muy diversa, se realizó una estandarización a partir de un valor "base", con la fórmula siguiente:

$$
V e=\frac{V m}{V b}
$$

Dónde: $\mathrm{Vm}=$ Valor medido de cada productor en los indicadores; $\mathrm{Vb}=$ valor base definido en función del indicador y $\mathrm{Ve}=$ valor estandarizado en un rango de $0-1$.

Cabe aclarar que el valor base usado en la estandarización fue el máximo de cada variable, exceptuando demanda de mano de obra, ingreso por especies adicionales al café y densidad de plantación, donde se consideró la media debido a la presencia de valores extremos. Para estas variables debido a que se obtuvieron Ve $>1$, se realizó una segunda estandarización tomando como base al máximo de la primera estandarización.

Una vez obtenidos los Ve, se procedió a sumarlos para así obtener el promedio con la formula siguiente:

$$
I S_{i}=\frac{\sum_{j-1}^{n} V e_{j n}}{n}
$$

Dónde: $\mathrm{IS}_{\mathrm{i}}=$ índice de sostenibilidad del $\mathrm{i}$-ésimo productor; $\mathrm{Ve}_{\mathrm{jn}}=$ Valor estandarizado del j-ésimo indicador de $\mathrm{n}$ indicadores y $\mathrm{n}=$ número total de indicadores.

Posteriormente los IS se clasificaron en diferentes categorías, basadas en Masera et al. (2000): insostenible $(0,0-0,2)$; poco sostenible $(0,21-0,4)$; regularmente sostenible $(0,41-0,6)$; medianamente sostenible $(0,61-0,8)$ y sostenible $(0,81-1,0)$.

En cuanto al INAI, éste es un instrumento diseñado para medir la capacidad de innovación que posee un productor (Muñoz et al., 2007), considerando el número de prácticas tecnológicas que realiza en un momento determinado, sobre un número de prácticas totales definidas en un catálogo (Ecuación 1). Cabe señalar, que este valor, también, oscila entre 0-1. En el catálogo de innovaciones propuestas se indica el porcentaje de las mismas que adoptan los productores.

$$
I N A I_{i}=\frac{\sum_{j-1}^{n} I_{n n o v}{ }_{j n}}{n}
$$


Dónde: $\mathrm{INAI}_{\mathrm{i}}=$ índice de adopción de innovaciones del i-ésimo productor; Innov $_{\mathrm{jn}}=$ presencia de la j-ésima innovación de $\mathrm{n}$ innovaciones y $\mathrm{n}=$ número total de innovaciones.

Finalmente, la información obtenida se procesó utilizando el software estadístico SPSS ${ }^{\circ}$ V. 23, con el cual, se obtuvo estadística descriptiva para el perfil de los grupos, pruebas de comparación de medias en rendimientos, precios, jornales, densidad de plantación, especies manejadas e ingresos; de igual manera análisis de varianza y correlaciones simples. Es importante señalar que debido a que las variables analizadas no se distribuyen normalmente según el estadístico de Kolmogorov-Smirnov, se usó estadística no paramétrica con la prueba de $\mathrm{H}$ Kruskal Wallis y U- Mann Whitney para la comparación de medias.

\section{Resultados y discusión}

A continuación, se presentan los indicadores que tuvieron diferencias estadísticamente significativas, mismos que se desglosan de acuerdo al atributo para el que fueron considerados.

\subsection{Primer atributo: productividad}

Los indicadores aquí propuestos tuvieron diferencias estadísticamente significativas entre los grupos de productores, con mejores cifras para los asociados, como a continuación se demuestra.

\section{Rendimiento}

En los ciclos analizados los asociados obtuvieron en promedio 126 y $138 \mathrm{Kg} / \mathrm{ha}$, más que los no asociados en la cooperativa $(\mathrm{p}<0,05)$, y para facilitar la comprensión se presentan los rendimientos exactos de estos productores en la Tabla 4.

Tabla. 4. Rendimientos de café ciclos 2014 -2015 y 2015 -2016.

\begin{tabular}{|c|c|c|c|c|c|}
\hline \multirow[t]{2}{*}{ Ciclo } & \multicolumn{2}{|c|}{ No asociados } & \multicolumn{2}{|c|}{ Asociados } & \multirow[b]{2}{*}{ P. Value } \\
\hline & $\begin{array}{l}\text { Media } \\
\text { (Kg/ha) }\end{array}$ & $\mathbf{C V}$ & $\begin{array}{l}\text { Media } \\
\text { (Kg/ha) }\end{array}$ & $\mathbf{C V}$ & \\
\hline Ciclo 2014-2015 & 155,65 & 71,42 & 282,18 & 52,53 & $\mathrm{P}<0,01$ \\
\hline Ciclo 2015-2016 & $111,05^{\prime \prime}$ & 78,42 & 249,25 & 87,12 & $\mathrm{P}<0,01$ \\
\hline
\end{tabular}

Nota: Superíndices distintos $\left({ }^{\mathrm{a}} \mathrm{y}^{\mathrm{b}}\right)$ en la misma fila indican diferencias estadísticamente significativas $(\mathrm{p}<0.05)$. Según prueba de $\mathrm{H}-$ Kruskal Wallis y U- Mann Whitney. Fuente: Elaboración propia con base en información de campo, 2016.

A partir de estos datos se observa que los asociados superaron la media municipal y estatal $(80.5$ y $216.2 \mathrm{Kg} / \mathrm{ha})$ (SIAP, 2016). Por otra parte, los 
rendimientos señalados coinciden con los reportados por Coutiño y Santoyo (2016), quienes encontraron 195.5 y $247,2 \mathrm{Kg} / \mathrm{ha}$ para el mismo ciclo en productores socios de las organizaciones Yeni Navan y UNECAFE del mismo estado, y $115 \mathrm{Kg} / \mathrm{ha}$ para no asociados cooperativos. También, son similares a los de Pérez-Grovas (2000), que reporta una diferencia de $60 \mathrm{~kg}$ entre el sistema orgánico y tradicional en Majomut, Chiapas, donde los del primer sistema están organizados.

Este hecho se destaca como logro importante de la asociación y resultado de mejores prácticas en la finca, que conducen a la obtención de un producto de calidad y mejores precios a través del acceso directo al mercado (Rodríguez y Ramírez, 2016). También, se observa que las relaciones en el interior de la organización y su articulación con la CEPCO, representan un instrumento de ayuda mutua que fomenta la confianza, trabajo en grupo, y compromiso con la organización; vínculos que permiten acceder a recursos importantes como tecnología, información y recursos materiales para la mejora del sistema de producción como ventaja de las relaciones sociales.

Por ello, se debe promover la cooperación y acciones que desarrollen la filosofía cooperativista y generen visión de acción colectiva territorial de acuerdo con lo planteado por Ostrom (2004), en conjunto con temas que garanticen la construcción de capital social, por medio de relaciones de confianza entre asociados, compromiso para lograr planes construidos de manera participativa y fortalecimiento de capacidades tecnológicas.

\section{Demanda de fuerza de trabajo}

Este indicador consideró limpia y cosecha del cafetal y reflejó que los no asociados emplean para la primera actividad veinticinco jornales, calculados de la siguiente forma: 1,9*13,2 (trabajadores promedio por día* número total de días que dura la actividad por ha); mientras que los asociados únicamente demandan nueve $(1,2 * 7,09)$. En cuanto a la cosecha, los primeros emplean $35,3(2,6 * 13,6)$ jornales y los asociados $30,3(3,7 * 8,2)$ (Ver Tabla 5). 
Tabla. 5. Jornales invertidos en el sistema de producción cafeticultor en la limpia y cosecha por hectárea.

\begin{tabular}{lllllllll}
\hline & & \multicolumn{6}{c}{ No asociados (n=26) } & \multicolumn{4}{c}{ Asociados (n=54) } & \\
& Indicador & Media & Rango & CV & Media & Rango & CV & P. Value \\
\hline Limpia & Jornales/ha & $1,9^{\mathrm{b}}$ & $0,3-6$ & 78,47 & $1,2^{\mathrm{a}}$ & $0,4-2,7$ & 46,95 & $\mathrm{P}<0,01$ \\
& & & & & & & \\
& Días de act. & $13,2^{\mathrm{b}}$ & $1,4-42$ & 68,65 & $7,09^{\mathrm{a}}$ & $1,6-15$ & 38,77 & $\mathrm{P}<0,01$ \\
Cosechann & Jornales/ha & $2,6^{\mathrm{a}}$ & $0,30-8$ & 72,67 & $3,7^{\mathrm{b}}$ & $1,3-7,5$ & 42,09 & $\mathrm{P}<0,01$ \\
\multirow{2}{*}{ Total } & Días de act. & $13,6^{\mathrm{b}}$ & $1,3-50$ & 65,12 & $8,2^{\mathrm{a}}$ & $0,7-30$ & 67,87 & $\mathrm{P}<0,01$ \\
& Jornales/ha & $\mathbf{6 0 , 4 4}$ & & & $\mathbf{3 8 , 8 4}$ & & & \\
& Superf. (ha) & $1,7^{\mathrm{a}}$ & $1-10$ & & $3,8^{\mathrm{b}}$ & $0,5-8$ & & $\mathrm{P}<0,01$ \\
\hline
\end{tabular}

Superíndices distintos $\left({ }^{\mathrm{a}} \mathrm{y}^{\mathrm{b}}\right)$ en la misma fila indican diferencias estadísticamente significativas. Según prueba de H -Kruskal Wallis y U- Mann Whitney. Fuente: Elaboración propia con base en información de campo, 2016.

Analizada esta variable en todo el sistema representa un factor de insostenibilidad, sin embargo, al separar los grupos, resulta sostenible para los asociados. Pero se destaca que la cosecha es la actividad que demanda más jornales e impacta en los costos, planteando para los no asociados cooperativos la necesidad de una estrategia que nivele la relación mano de obra-productividad, como es el caso de los asociados donde los mayores volúmenes de producción y menores jornales (Figura 2), se explican por el establecimiento de un plan de trabajo que define actividades y control de ritmos de trabajo, para cumplir con los estándares de certificación orgánica que les impone el mercado.

Figura. 2. Escenarios de producción de asociados y no asociados.

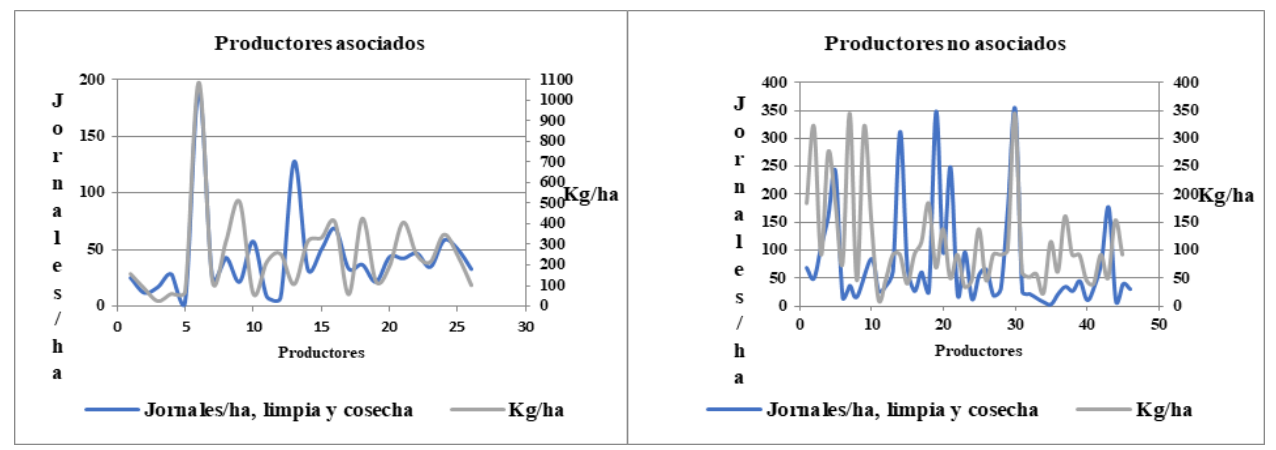

Fuente: Elaboración propia con base en trabajo de campo, 2016. 
En este indicador Pérez-Grovas (2000), en Majomut Chiapas, reportó 79,4 y 60,1 trabajadores/ha, para los sistemas café orgánico y tradicional, respectivamente, con trabajadores destinados a la poda de árboles sombra, conservación de suelo y elaboración y aplicación de abonos orgánicos. Por otra parte, a través de este indicador se destaca la especialización de la mano de obra para la ejecución de prácticas de manejo en el interior de la parcela, como característica propia de los asociados y resultado de capacitaciones constantes encaminadas a la obtención de un producto de calidad con certificaciones internacionales, con lo cual se mejora la competitividad de la asociación cooperativa.

\section{Densidad de plantación}

Indicador que le confiere mayor sostenibilidad al sistema cafetalero regional cuando se considera de manera general sin separar a los asociados de los no asociados en la cooperativa. De esta forma, el promedio de todos los encuestados fue de 1.900 plantas /ha, los no asociados reportan 1.951, mientras que los agremiados señalan tener 1.791. Es importante señalar que estos datos sobrepasan lo reportado en el Plan de innovación de la cafeticultura en Oaxaca (SAGARPA, 2011), que señala un rango de 900 a 1.300 plantas /ha, pero coinciden con los resultados de Ejea (2009), quien encontró en Xalapa-Coatepec, Veracruz, 1.800$2.000 \mathrm{plantas} / \mathrm{ha}$, en parcelas encaminadas a aumentar el rendimiento, y 1.2001.500 plantas /ha en sistema tradicional con sombra de policultivo.

En países cafetaleros como Colombia, Araque (2015) reportó para fincas grandes con alto nivel tecnológico promedios de 6.643 árboles/ha, mientras que Dussán, Duque y González (2006), encontraron 5.015 plantas/ha, datos que contrastan con la zona estudiada por su naturaleza de pequeños productores.

La densidad es uno de los elementos que mayor influencia tiene sobre la productividad (Araque, 2015), y por consiguiente, debe ser considerada en la definición de estrategias tecnológicas instrumentadas para elevar los rendimientos y en torno a esto, la cooperativa ha formado la cultura de mantenimiento y manejo de la parcela, que crea un sistema resiliente, favorecido por el desarrollo de capacidades tecnológicas, repercutiendo en la mejora continua del sistema en una visión prospectiva, que en el largo plazo impacta en los no asociados cooperativos al limitar su marginalidad tecno-social.

Lo anterior debido a que las sociedades cooperativas están vinculadas a la comunidad local de la que emergen (Calvo y González, 2011) y son resultado de una dinámica social del territorio que puede partir de un interés de un determinado grupo o general.

\subsection{Segundo atributo: estabilidad, resiliencia y confiabilidad}

La literatura señala que como respuesta a las nuevas necesidades sociales, se deben plantear modelos socioeconómicos sostenibles y responsables, por ello, en el ámbito social y ambiental se evaluaron los indicadores de este atributo, mismos que presentaron diferencias estadísticamente significativas entre los grupos de productores. 


\section{Número de especies manejadas y árboles sombra}

Se encontró que el sistema de producción de los asociados presenta mayor biodiversidad, al poseer diez especies distintas que suman árboles sombra y tipos adicionales, mientras que los no asociados en la cooperativa únicamente tienen cuatro (Tabla 6). Cabe mencionar, que se consideró el número de especies de árboles sombra y frutales que pueden generar, además, otros ingresos.

Tabla. 6. Especies útiles en cafetales para productores asociados y no asociados.

\begin{tabular}{llll}
\hline Indicador & No asociados & Asociados & P.Value \\
\hline Spp de sombra & $2^{\mathrm{a}}$ & $5^{\mathrm{b}}$ & $\mathrm{P}<0.01$ \\
Otras spp & $2^{\mathrm{a}}$ & $5^{\mathrm{b}}$ & $\mathrm{P}<0.01$ \\
Total spp & 4 & 10 & $\mathrm{P}<0.01$ \\
Árboles sombra & $68.81^{\mathrm{a}}$ & $69.3^{\mathrm{a}}$ & 0.966 \\
\hline
\end{tabular}

Nota: Superíndices distintos $\left({ }^{\mathrm{a}} \mathrm{y}^{\mathrm{b}}\right)$ en la misma fila indican diferencias estadísticamente significativas. Según prueba de H -Kruskal Wallis y U- Mann Whitney. Fuente:

Elaboración propia con base en trabajo de campo, 2016.

Estos resultados se asemejan a los reportados por Pérez-Grovas (2000), quien encontró trece especies en el sistema orgánico y tres en el tradicional y en cuanto al número de árboles sombra (AS), los datos coinciden con el mínimo reportado por Rainforest Alliance (2005), de setenta árboles/ha y al menos doce especies nativas entre ellas, como parte del programa de sombra permanente.

En este punto, si se considera al territorio como determinante de la función de producción y el conocimiento sobre sus recursos y potencialidades como condición necesaria para maximizarla, la organización ha contribuido favorablemente, ya por medio de la asesoría técnica que impulsa la acción colectiva según Álvarez, Saiz, Díaz, Castillo y Herrera (2012), los agremiados han ido desarrollando capacidades tecnológicas, que les permiten conocer bondades de otras especies nativas que sirven como sombra y adoptarlas; mientras, que los no asociados en la cooperativa al carecer de apoyos técnicos, emplean en mayor medida la especie tradicional (Inga sp).

\section{Precio del café}

La diversidad de calidad y variedades del café complican el análisis de sus precios, pero de manera general, demuestran que su establecimiento depende de factores externos al productor, pero no por ello deja de afectarles; en el caso de los asociados su afectación es menor por articularse a mercados especializados y contar con otros factores de sostén (apoyos gubernamentales, fuentes de financiamiento, etc.), que garantizan un mejor precio de venta. En la Tabla 7, se puede observar el cumplimiento de lo anterior. 
Tabla. 7. Precios por Kg de café en dos ciclos de producción.

\begin{tabular}{llllll}
\hline $\begin{array}{l}\text { Ciclo } \\
\text { productivo }\end{array}$ & \multicolumn{2}{l}{ No asociado } & Asociado & P. Value \\
& $\mathbf{( \$ / K g )}$ & $\begin{array}{l}\text { Desviación } \\
\text { estándar }\end{array}$ & $\mathbf{( \$ / K g )}$ & $\begin{array}{l}\text { Desviación } \\
\text { estándar }\end{array}$ & \\
\hline $\mathbf{2 0 1 4 - 2 0 1 5}$ & $41,94^{\mathrm{a}}$ & 4,86 & $49,46^{\mathrm{b}}$ & 0 & $\mathrm{P}<0,01$ \\
$\mathbf{2 0 1 5 - 2 0 1 6}$ & $46,45^{\mathrm{a}}$ & 4,31 & $52,00^{\mathrm{b}}$ & 0 & $\mathrm{P}<0,01$ \\
\hline
\end{tabular}

Nota: Superíndices distintos $\left({ }^{a} y^{b}\right)$ en la misma fila indican diferencias estadísticamente significativas. Según prueba de H -Kruskal Wallis y U- Mann Whitney. Fuente:

Elaboración propia con base en trabajo de campo, 2016.

A pesar de que ambos grupos venden su producción en forma de café pergamino, los agremiados presentan mayor estabilidad económica conferida por la cooperativa, mientras los no asociados enfrentan la volatilidad, y dependen del ofrecido por el acopiador inmediato, generando fragilidad en su sistema de producción y unidad económica familiar. Por ello, se puntualiza que la relación UPIZS SUR- CEPCO, inserta el producto en una red de valor amplia que incrementa precios ofrecidos al productor, y los no asociados cooperativos se insertan al mercado a través de una relación unilineal con el proveedor de insumos y acopiador inmediato, garantizando únicamente un ingreso básico (Figura 3).

Sin embargo, cabe aclarar que los vínculos de la cooperativa con los elementos de la red de valor son indirectos y dados por la CEPCO, pero la relación con diversos actores clave permite a los socios ampliar sus posibilidades de posicionamiento comercial, y desarrollar, en el ámbito local-regional, un modelo de economía de escala sostenible, que unifica volúmenes de producción de forma programada y constante. 
Figura. 3. Red de valor de la UPIZS SUR.

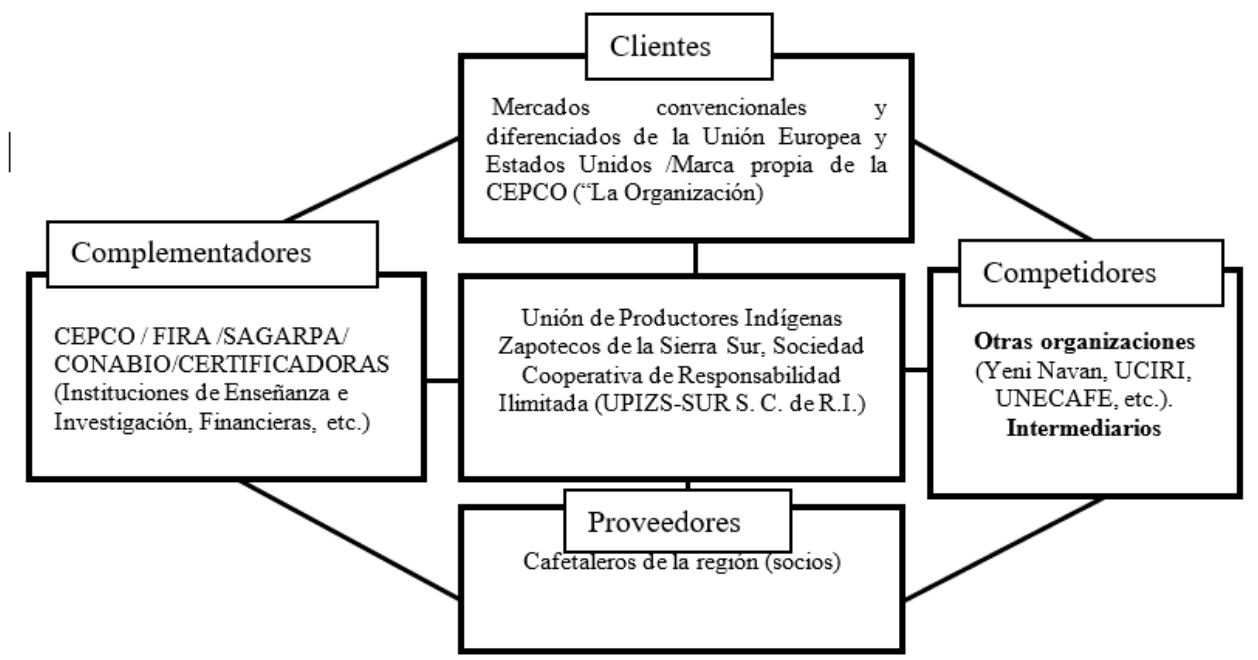

Fuente: Elaboración propia con base en trabajo de campo, 2016.

De este modo, se ve una clara desventaja para los no asociados en cuanto al precio recibido, pero a pesar de ello no buscan otros intermediarios, debido a la rapidez con que les pagan, ya que cuando los productores están desesperados por dinero rápido, prefieren vender su pequeña producción a intermediarios que pagan inmediatamente, aun cuando esto les reporte disminución de utilidad (BordaRodríguez y Vicari, 2015). Para los agremiados una situación así debilitaría el desempeño general de la cooperativa, por ello una estrategia que contribuye al logro de un compromiso del asociado con la sostenibilidad económica de su organización, es la comercialización del $100 \%$ de su producción a través de ésta (Álvarez, Saiz, Díaz, Castillo, y Herrera, 2012). Por ello, una ventaja de la asociatividad es el incremento de los márgenes económicos y la capacidad de enfrentar las amenazas del entorno (Amézaga, Rodríguez, Núñez, y Herrera, 2013).

\section{Ingreso por especies adicionales al café}

Basta señalar que con el rendimiento y precio del café del ciclo 2015-2016, se obtuvo el ingreso exclusivamente del aromático que fue de $\$ 12.959,47$ y $\$ 5.264,90$ para asociados y no agremiados, respectivamente. Mientras que el ingreso promedio anual obtenido por especies adicionales al café/ ha, en el caso de los agremiados fue de $\$ 12.911$ y para no asociados $\$ 5.964(\mathrm{P}<0,05)$.

Con los datos anteriores, se determinó el índice de diversificación de ingresos (ingreso adicional/ingreso total), que para los primeros fue de $50 \%$ $(\$ 12.911,1 / \$ 25.870,5)$ y de $53 \%$ para los segundos $(5.963,9 / 11.228,8)$, con lo cual se demuestra que en ambos grupos, ésta es una estrategia importante; aunque dicho índice difiere del reportado por Pérez-Grovas (2000), en productores de Chiapas $(21 \%)$, por la menor cantidad de especies presentes en el sitio. 
Los mayores rendimientos y la diversificación en el interior de la parcela como resultado de la asesoría técnica generan, como logro importante de la asociación, el incremento en el ingreso del productor y representan un potencial como indicador de sostenibilidad. En ese sentido, el cooperativismo tiene capacidad para resolver las nuevas necesidades sociales que han aparecido en las últimas décadas, y han originado la revitalización de la importancia de la Economía Social (Monzón y Chaves, 2012).

En el entorno global de la producción y comercialización, la tendencia hacia modelos sostenibles y responsables es debatida con una significativa importancia, y en relación a eso, este estudio demuestra que la economía social a través de las cooperativas, representa una oportunidad de cambio y de contribución, dado los principios y valores que la definen y sobre los que basa su funcionamiento (Guridi y Pérez, 2014). Sobre todo, en un escenario como el de México donde las cooperativas han sido obstaculizadas desde los círculos gubernamentales, y el análisis de su articulación en regiones donde están presentes resulta interesante, al mostrar que los atributos transferidos de la asociación al productor, desarrollan un proceso de mejora constante en el comportamiento de éste y sientan bases para el trabajo en equipo.

\subsection{Tercer atributo: adaptabilidad}

La adopción de innovaciones ha permitido a los asociados acceder a mercados especializados y así obtener sobreprecios por la venta de café.

Acceso a innovaciones tecnológicas, superficie por sistema e incidencia de plagas y enfermedades

De un catálogo de doce innovaciones analizadas los productores asociados presentaron un índice de adopción de 0,92; mientras, que los no agremiados únicamente alcanzaron el 0,65 , con diferencias estadísticamente significativas $(\mathrm{P}<0,01)$ (Tabla 8).

Tabla. 8. Innovaciones propuestas para productores cafeticultores.

\begin{tabular}{|c|c|c|c|}
\hline \multirow[b]{2}{*}{ Núm. } & \multirow[b]{2}{*}{ Tipo de innovación } & \multicolumn{2}{|c|}{ Tipo de productor } \\
\hline & & $\begin{array}{l}\text { No } \\
\text { asociado }\end{array}$ & Asociado \\
\hline 1 & Renovación cafetos & 1,00 & 1,00 \\
\hline 2 & Árboles sombra (AS) & 1,00 & 1,00 \\
\hline 3 & Regulación sombra & 0,83 & 1,00 \\
\hline 4 & Control de plagas y enfermedades (PyE) & 0,28 & 1,00 \\
\hline 5 & Despulpadora propia & 0,67 & 1,00 \\
\hline 6 & Conservación de suelos & 0,85 & 1,00 \\
\hline 7 & Patio de secado & 0,30 & 0,08 \\
\hline 8 & Asistencia técnica & 0,61 & 1,00 \\
\hline 9 & Fertilización orgánica & 1,00 & 1,00 \\
\hline 10 & Diversificación Spp & 0,35 & 1,00 \\
\hline
\end{tabular}




\begin{tabular}{llll}
\hline 11 & Bitácoras & 0,07 & 1,00 \\
12 & Apoyos instituciones públicas y privadas & 0,87 & 1,00 \\
& Promedio & $\mathbf{0 , 6 5}$ & $\mathbf{0 , 9 2}$ \\
\hline
\end{tabular}

Fuente: Elaboración propia con base en trabajo de campo, 2016.

En la Figura 4, se observa el comportamiento de cada grupo y se destaca que dado el carácter orgánico del sistema de producción, el control y prevención de plagas y enfermedades para los asociados es permanente, con énfasis en labores culturales. En el caso de los no asociados no existe tal manejo y enfrentan el riesgo constante de plagas o enfermedades.

Figura. 4. Índice de adopción de Innovaciones (INAI).

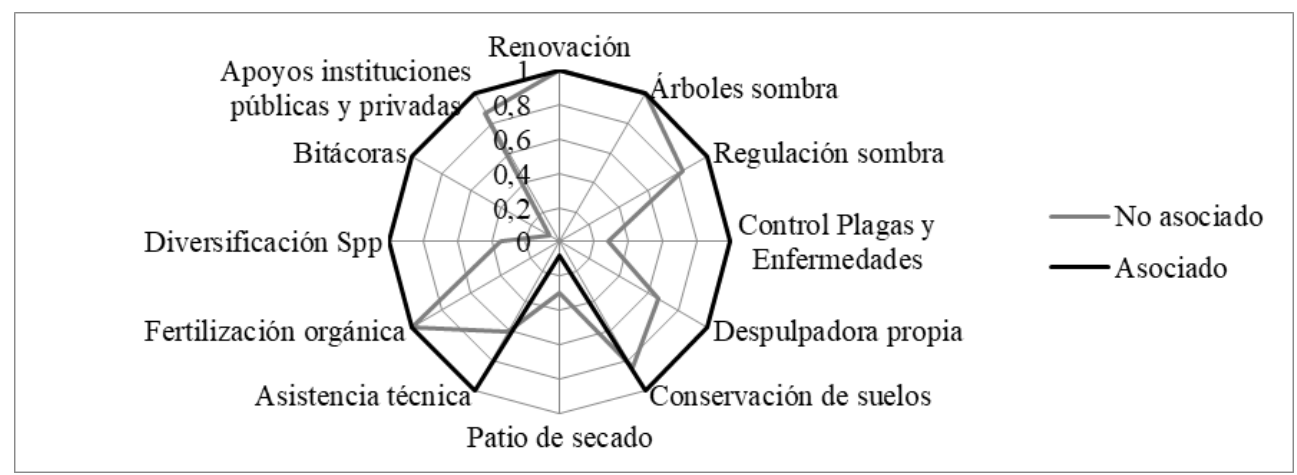

Fuente: Elaboración propia con base en datos de campo, 2016.

A pesar de que la incidencia de plagas y enfermedades pertenece al segundo atributo, el análisis se realiza en esta sección por su vinculación con el INAI. En ese sentido, para demostrar la variación existente entre ambos grupos, se realizó una prueba $\mathrm{X}^{2}$ de Pearson, que demostró que efectivamente existe relación entre el hecho de estar asociado y el control de agentes patógenos $(\mathrm{P}<0,01)$, un control que puede deberse a la mayor superficie de este grupo ( $3.8 \mathrm{ha}$ ) comparada con la de los no asociados $(1,7 \mathrm{ha})$ con diferencias estadísticamente significativas $(\mathrm{P}<0,01)$.

Con estos resultados se cumple lo señalado por Borda-Rodriguez y Vicari (2015), al destacar que la adopción de innovaciones ayuda a la cooperativa a satisfacer necesidades de sus miembros, demanda del mercado y acceso a mercados exigentes. Este proceso se vincula con un plan de desarrollo de capacidades continuo que fortalece el desarrollo tecnológico y produce mejoras en la competitividad, productividad y resistencia a los cambios externos no controlados, como el ingreso de nuevos productos, políticas y regulaciones ambientales (Valdez-Vazquez, Sánchez y Escalante, 2017). 


\subsection{Cuarto atributo: Autogestión}

La capacitación es un factor relevante en el desarrollo de procesos autogestivos, ya que de ahí se deriva parte del conocimiento que tienen del proceso productivo y comercial, y fue determinante en el fortalecimiento del sistema de producción.

\section{Productores capacitados}

La capacitación de los asociados se realiza a partir de técnicos comunitarios instruidos y apoyados por personal de la CEPCO y externos; son hijos de los socios, por lo general, han cursado la educación media superior o superior, y elegidos mediante asamblea de socios. Actualmente, participan de manera permanente tres técnicos regionales, sumados a los estatales que proporcionan la CEPCO y el gobierno federal y en cuanto a mecanismos de transferencia de tecnología resaltan las demostraciones de campo, asambleas mensuales de información y recomendaciones técnicas recibidas en procesos de inspección de los cafetales. En tanto, que el $61 \%$ de los no asociados en la cooperativa ha recibido en promedio una visita de algún técnico, que en la mayoría de los casos ha ocurrido en periodos discontinuos (de tres - quince años entre cada visita).

Derivado de este indicador, el hecho de involucrar a los productores por medio de metodologías participativas en la identificación de necesidades y planteamiento de alternativas de solución, contribuye a elaborar planes ajustados a sus necesidades y a mejorar su compromiso con los procesos de intervención (Américo, Aoki, Bosisio, Amorim y Fontes, 2013), favoreciendo la creación de lazos de liderazgo tecnológico, familiaridad, confianza, y resultados parciales en el corto plazo, como una acción determinante para mantener el interés de los productores en la organización (IICA, 2009).

Por último, desde el ámbito interno de las cooperativas una de las ventajas a destacar, son sus procesos de toma de decisiones basados en valores y criterios democráticos; y desde la perspectiva externa se puede afirmar que al surgir estas actuaciones de la "dinámica endógena del territorio", las cooperativas, a diferencia de otro tipo de empresas convencionales, no deslocalizan su actividad productiva ya que se encuentran vinculadas al territorio (Demoustier, 2011).

\section{Índice de sostenibilidad (IS)}

En la medición de este índice se obtuvo que el rendimiento es el indicador con menor valor $(0,22)$ y muestra situaciones insostenibles que afectan al ámbito económico y ambiental, por lo que el atributo de productividad presenta mayor fragilidad (Tabla 9). Caso contrario, se da en las variables precios del café $(0,85)$, densidad de plantación $(0,77)$ y acceso a innovaciones tecnológicas $(0,74)$, factor asociado a las gestiones realizadas por la organización (Figura 5). En el caso de la mano de obra, resulta ser un factor que provoca insostenibilidad en el sistema. 
Tabla. 9. Valores medios, estandarizados y base para cada indicador.

\begin{tabular}{|c|c|c|c|c|c|}
\hline Indicador & Dimensión & Unidades & $\begin{array}{l}\text { Valor } \\
\text { base }\end{array}$ & $\begin{array}{l}\text { Valor } \\
\text { medio }\end{array}$ & $\begin{array}{c}\text { Valor } \\
\text { estandarizado } \\
\text { promedio }\end{array}$ \\
\hline i1. Rendimiento & A & $\mathrm{Kg} / \mathrm{ha}$ & 796,0 & 174,91 & $\overline{0,22}$ \\
\hline $\begin{array}{l}\text { i2. Demanda de fuerza } \\
\text { de trabajo }(L+C)\end{array}$ & $\mathrm{E}$ & $\begin{array}{l}\text { Jornales } \\
\text { /ha }\end{array}$ & 60,0 & 60,0 & 0,37 \\
\hline $\begin{array}{l}\text { i3. Número de spp } \\
\text { manejadas }(\mathrm{AS}+\mathrm{OSp})\end{array}$ & A & $\mathrm{Sp} / \mathrm{ha}$ & 12,0 & 4 & 0,35 \\
\hline $\begin{array}{l}\text { i4. Ingreso por otras } \\
\text { especies }\end{array}$ & $\mathrm{E}$ & $\$ /$ ha & $9.977,9$ & $9.977,9$ & 0,60 \\
\hline i5. Densidad & A & Plantas/ha & $1.791,2$ & $1.791,2$ & 0,77 \\
\hline i6. Precios del café & $\mathrm{E}$ & $\$ / \mathrm{Kg}$ & 56,52 & 48,3 & 0,85 \\
\hline $\begin{array}{ll}i 7 . & \text { Productores } \\
\text { capacitados } & \end{array}$ & $\mathrm{S}$ & $\begin{array}{l}\text { Visitas } \\
\text { /año }\end{array}$ & 12,0 & 4,7 & 0,38 \\
\hline i8. INAI & $\mathrm{S}$ & Coeficiente & 1,0 & 0,74 & 0,74 \\
\hline
\end{tabular}

$i$ : indicadores de sostenibilidad. Fuente: Elaboración propia con base en trabajo de campo, 2016.

Figura. 5. Índice de Sostenibilidad de cafeticultores de la región Loxicha, Oaxaca.

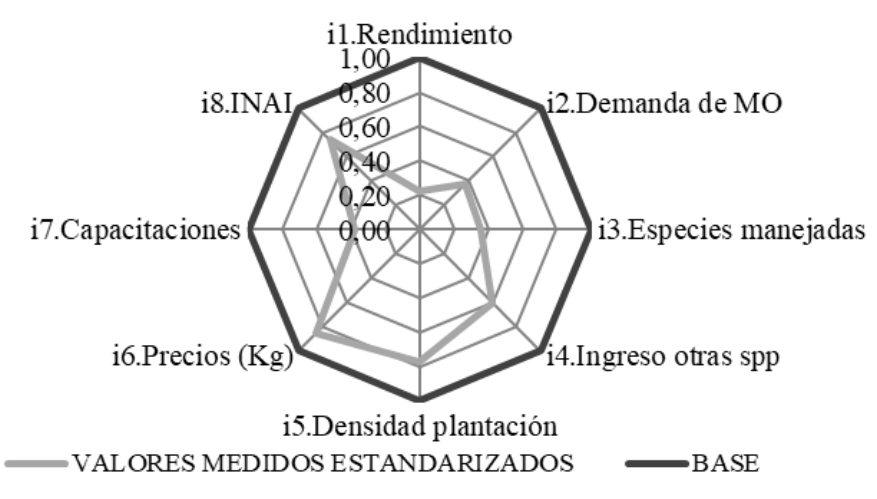

Fuente: Elaboración propia con base en información de campo, 2016.

La media general de todo el sistema, sin importar si estaban asociados o no, fue de 0,52 , que lo clasifica como regularmente sostenible. Sin embargo, al separar los grupos, el sistema de agremiados presenta mayor sostenibilidad $(0,73)$, debido a las acciones desempeñadas por la cooperativa; mientras, que, los no agremiados alcanzaron únicamente un promedio de 0,43 , que clasifica al sistema como regularmente sostenible, con un $88,9 \%$ de productores por debajo de la media general $(0,52)$ (Figura 6). 
Figura. 6. Índice de Sostenibilidad para productores asociados o no de la región Loxicha, Oaxaca.

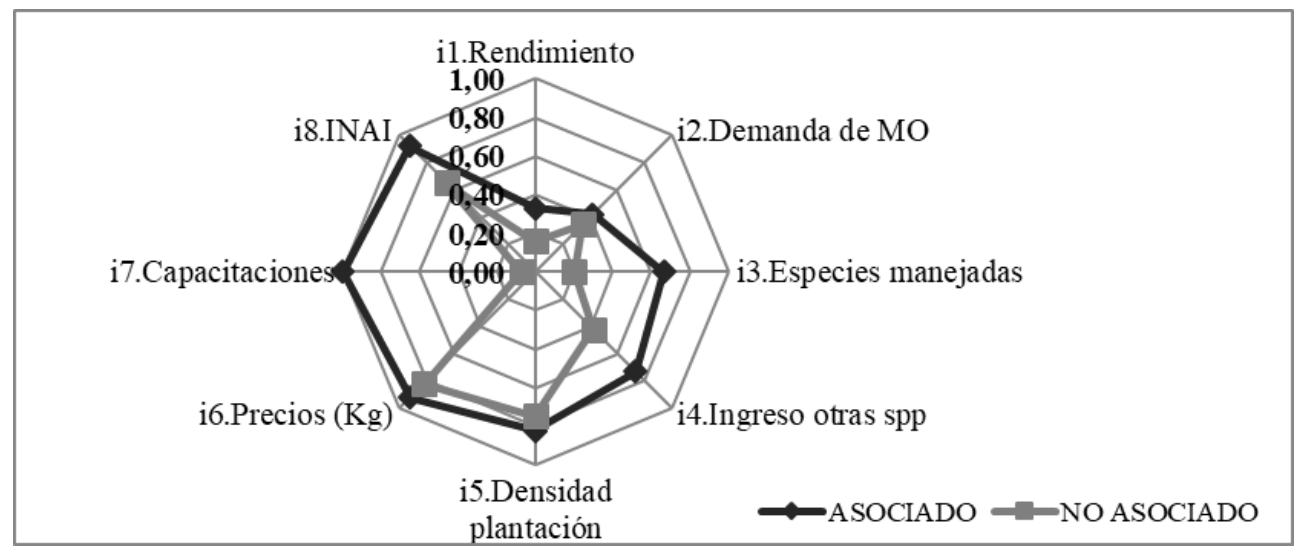

Fuente: elaboración propia con base en información de campo, 2016.

Finalmente, se graficó el índice de sostenibilidad obtenido para cada productor, donde se observa que el sistema de producción de asociados muestra mayor sostenibilidad (Figura 7).

Figura. 7. Índice de sostenibilidad por tipo grupo y brecha en el IS por productor.

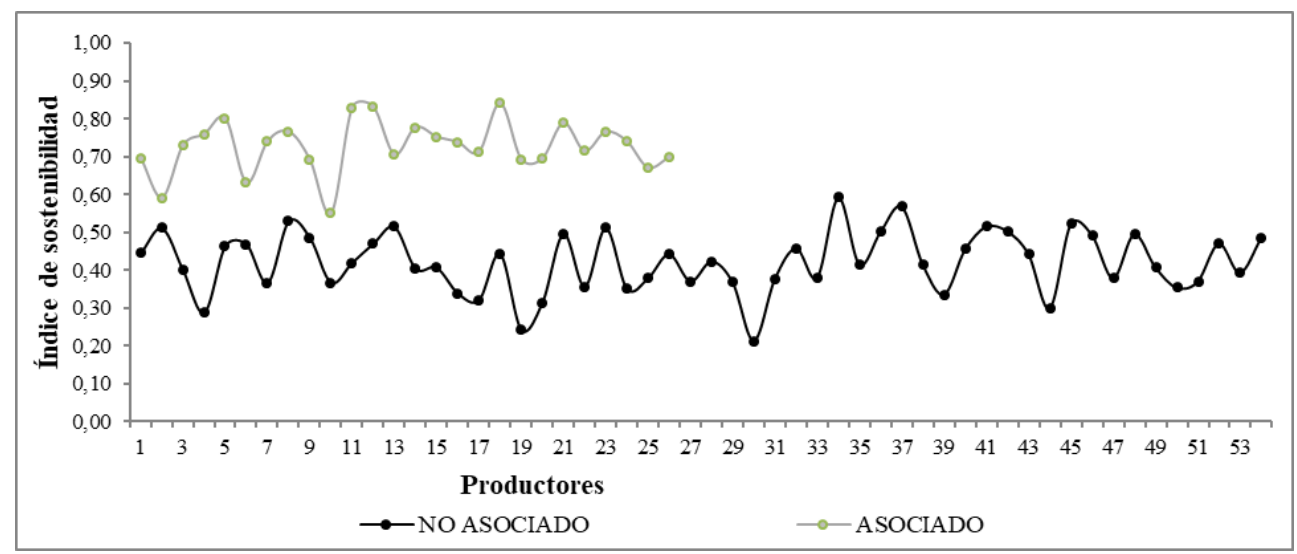

Fuente: Elaboración propia con base en información de campo, 2016. 
Figura. 8. Índice de sostenibilidad por tipo grupo y brecha en el IS por productor

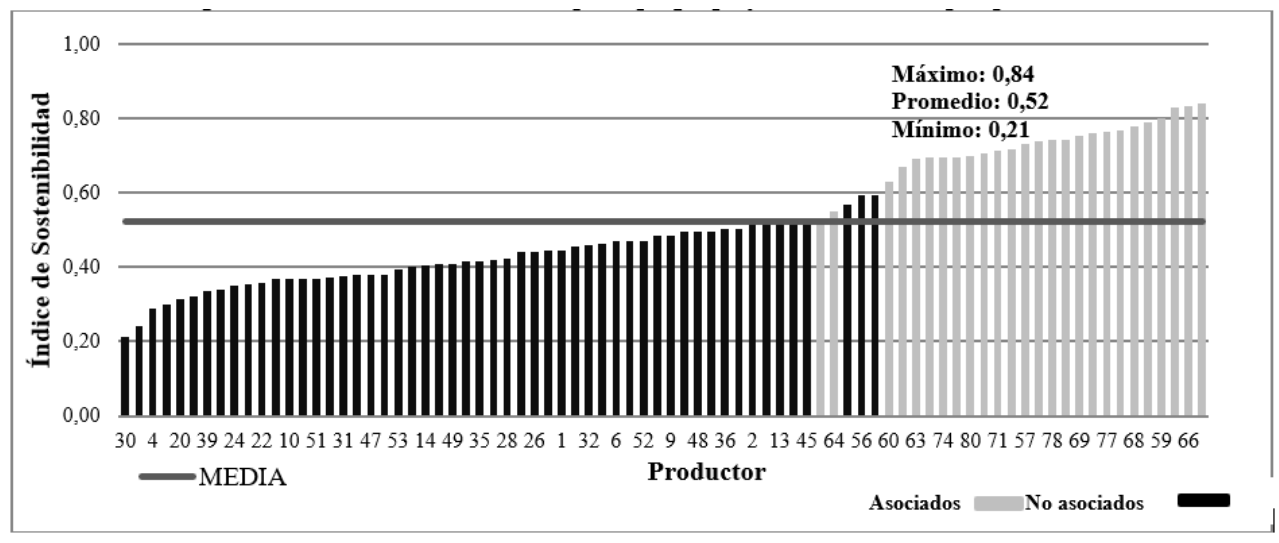

Fuente: Elaboración propia con base en información de campo, 2016.

Se observó una brecha en el IS de los productores de 0,63 (Figura 8), lo cual refleja la existencia de productores cuya forma de producir es sostenible y otros que no. Finalmente, estableciéndose dos grupos: productores en clasificación sostenible (Índice $\geq 0,5)$ e insostenible $(<0,5)$, con una prueba $X^{2}$ de Pearson se demostró que existe relación entre estar asociado y la sostenibilidad del sistema $(\mathrm{P}<0,01)$ y que el $14,8 \%$ de no asociados en la cooperativa están en calidad de sostenible, mientras, que en los agremiados fue el $100 \%$, situación relacionada con la obtención de sobreprecios, acceso a innovaciones tecnológicas y a capacitaciones constantes (Figura 9).

Figura. 9. Relación asociación-sostenibilidad.

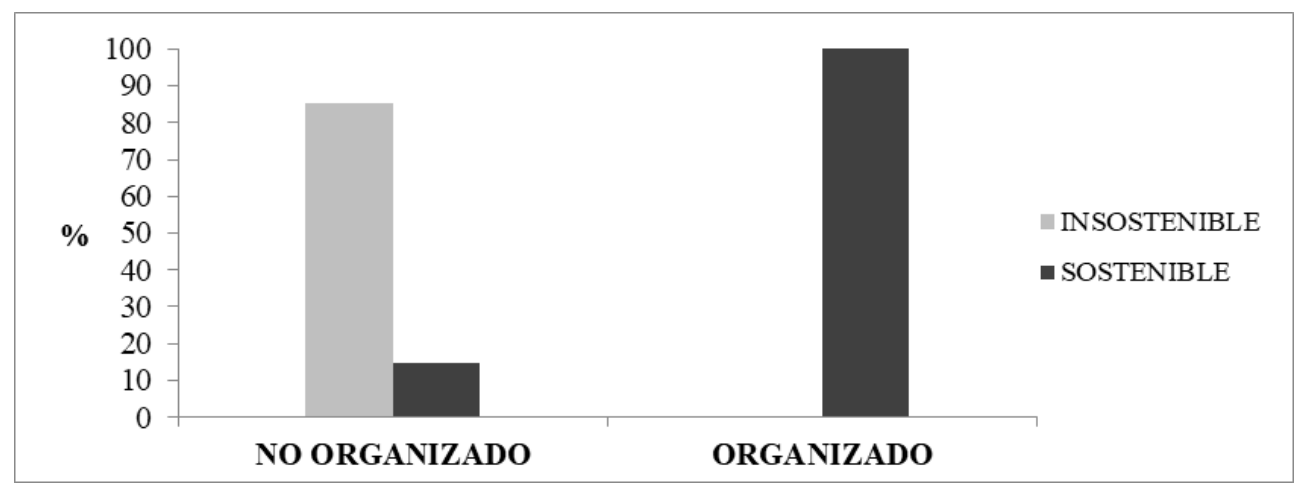

Fuente: Elaboración propia con base en información de campo, 2016.

Se añade que el $95 \%$ de los no asociados expresó su deseo de integrarse a una cooperativa, manifestando que la principal razón del por qué no lo han hecho es el 
desconocimiento como consecuencia de la falta de promoción por parte de las mismas.

En general, la forma en la que se integran los productores al mercado es un factor que influye en el IS; los no asociados en la cooperativa, por su escaso acceso a factores incidentes en el desarrollo competitivo, tienen como única opción de comercialización los intermediarios locales y baja rentabilidad, pero pese a esto, no han renunciado a la actividad debido a que de ella obtienen un producto de autoconsumo, y forma parte de su herencia socio técnica y cultural.

Con esta contribución se ha comprobado lo señalado por Lele (1981); Rondot y Collion (2001); Ramírez et al. (2006); y Remy y Glave (2007), al señalar que las organizaciones proporcionan a sus miembros múltiples beneficios como: obtención a bajo costo de insumos agrícolas y de créditos, que la asociación procese y comercialice sus productos, certidumbre al asegurar que la calidad del producto se ajuste a la demanda, entre otros. Además, se evidencia la potencialidad que tiene la asociatividad para mejorar las condiciones de los pequeños productores en el acceso al mercado, y se plantea como uno de los retos de la promoción de la asociatividad el logro de la adopción de un enfoque de mercado, que permita a sus asociados beneficiarse de las economías de escala generadas de la acción colectiva (Amézaga et al., 2013).

De manera particular, se potencializa el papel que la UPIZS SUR en conjunto con la CEPCO, desempeñan en la región al permitir a sus socios tener conocimiento de que proveen a mercados más amplios, sofisticados y solidarios, contribuyendo en la creación de un sentido de pertenencia.

\section{Conclusiones}

Se ha destacado la importancia que tiene la asociación cooperativa en los productores de café, al confirmar que los niveles de sostenibilidad están influidos por el tipo de productor, siendo el escenario de los asociados cooperativos el que mayores valores presenta $(0,73$ vs 0,43$)$; con relación al objetivo de ubicar los determinantes de dicha sostenibilidad, se obtuvo que destacan los mejores rendimientos, mayores superficies y precios recibidos, así como el acceso a capacitación y asesoría técnica y mayor diversidad de especies, que en el caso de los no asociados presentan valores bajos y provocan insostenibilidad en su sistema de producción en los tres ejes incluidos, generando que su única opción de comercialización sea los intermediarios locales, lo cual disminuye la rentabilidad. En ese sentido la asociación cooperativa de los productores ofrece una oportunidad para afrontar la problemática, es una alternativa para mejorar el IS en cafeticultores de la zona de estudio.

La UPIZS SUR representan un agente de transformación socioeconómica que abre expectativas de éxito en este territorio caracterizado por su alto grado de marginación y escala de producción pequeña con diversas limitaciones, ya que al integrar a los productores en su ámbito comercial les posibilita acceder a diversos apoyos que mejoran su desarrollo tecnológico y productivo, mismo que se refleja en un Índice de Adopción de Innovaciones de 0, 92, posibilitado que puedan de forma indirecta enfrentar la competencia internacional. Por ello, para su 
permanencia debe planear una estrategia de asociación con enfoque territorial, abordando alternativas multidimensionales que propicien su desarrollo con cambios estructurales basados en la diversificación agrícola y la extensión de la cadena a los eslabones industriales y comerciales, buscando la posibilidad de desarrollo de una comunidad que tiene como sostén económico la producción y venta de café.

Los cafetaleros en coordinación con la cooperativa deben establecer líneas de acción correspondientes a los ejes económico, social y ambiental para contribuir a la permanencia de la actividad en el largo plazo; pero la heterogeneidad de los productores en cuanto al nivel de sostenibilidad, sugiere que las estrategias instrumentadas por los propios campesinos, organizaciones y programas de apoyo al sector, deben ser específicas para cada tipo, por ello, antes de ser difundidas deben ser seleccionadas de acuerdo a sus condiciones y características, correspondiendo a los tres planos de sostenibilidad, con énfasis en el manejo territorial y de innovaciones adecuadas, de ecosistema con potenciales resilientes, atributos sociales y desde luego estrategias de producción y comercialización para sostener la organización.

Para impulsar la economía social solidaria de la región y contribuir en el IS, la cooperativa dentro de su programa de desarrollo debe considerar estrategias orientadas a promocionar y promover entornos asociativos, puesto que la forma en que se integran los productores al mercado es factor determinante del IS y un elemento favorecedor para tal situación, es que gran parte de los no asociados en la UPIZS SUR (95\%) están dispuestos a integrarse a una cooperativa cafetalera, situación que no se ha concretado debido al desconocimiento como consecuencia de la escasa o nula promoción por parte de las mismas.

Por último, se destaca el aporte del presente trabajo, el cual consistió en evidenciar la importancia de las cooperativas cafetaleras en comunidades marginadas, a través de evidencia empírica que puede ser retomada por productores y agentes promotores de la asociatividad cooperativa, y en ese sentido, se sugiere que en futuras líneas de investigación se analicen situaciones relacionadas con modelos de negocio de ambos escenarios y especialización agrícola y territorial en el cultivo de café, para en su conjunto promover el desarrollo local y rural.

\section{Referencias bibliográfícas}

ACI. (2014) Principios y valores cooperativos. Publicado on line disponible en: http://www.aciamericas.coop/principios-y-valores-cooperativos-4456.

Álvarez, S. Y., Saiz, V. J. E., Díaz, M. R. D., Castillo, R. D. y Herrera, G. A. (2012) La Cooperativa de Productores Agropecuarios de Lenguazaque, el Valle de Ubaté y municipios circunvecinos (Coopalac) y su impacto en el desarrollo rural del municipio de Lenguazaque,Cundinamarca. Gest. Soc, Vol. 5, Nㅜ 2, pp. 51-73.

AMECAFE (2012) Plan integral de promoción del Café de México. Publicado online disponible en: http://infocafes.com/portal/wp-content/uploads/2016/04/pcm2012.pdf (consultado el 20/08/17).

Américo, M., Aoki, P., Bosisio, F., Amorim, B. y Fontes, L. (2013) A extensão rural na prática organizativa dos agricultores familiares da comunidade do Córrego do Mosquito, Jaguaré. Cuadernos de Agroecología, Vol. 8, N², pp. 1-4. 
Amézaga, C., Rodríguez, D., Núñez, M. y Herrera, D. (2013) Orientaciones Estratégicas para el Fortalecimiento de la Gestión Asociativa. IICA.

Araque, S. H. (2015) Variables tecnológicas que determinan la productividad de las fincas cafeteras del departamento de Caldas. Universidad Nacional de Colombia.

Bartra, A. (2006) Virtudes económicas sociales y ambientales del café certificado. In B. Canabal, C. B., Contreras, P. G. y León, L. A (Eds.), Diversidad rural: estrategias económicas y procesos culturales. México: Plaza y Valdés Editores, pp. 153-202.

Borda-Rodríguez, A. y Vicari, S. (2016) Coffee Co-operatives in Malawi: building resiliencie through innovation. Annals of Public and Cooperative Economics, pp. 317 338.

Calvo, P. R. y González, C. J. (2011) La creación de empresas de economía social en el modelo de desarrollo local: reflexiones sobre la divergencia actual del caso valenciano. REVESCO. Revista de Estudios Cooperativos, Primer Cuatrimestre, $\mathrm{N}^{\circ}$ 104, pp. 7-37. DOI: 10.5209/rev_REVE.2011.v104.1.

CONAPO (2010) Indice de marginación por localidad 2010. Publicado online disponible en:

http://www.conapo.gob.mx/en/CONAPO/Indice_de_Marginacion_por_Localidad_2010 (consultado el 15/11/15).

Coutiño, P. V. y Santoyo, C. V. H. (2016) Análisis comparativo de dos organizaciones de pequeños productores de café en Oaxaca, México. Mexico: CIESTAAM-UACh.

Demoustier, D. (2011) Les concepts philosophiques et sociaux de l'ESS dans ses rapports à l'activité économique et aux territoires. In Ndiaye, A. (Ed.), Économie sociale et solidaire: animation et dynamiques des territoires. Paris: L'Harmattan, pp. 47-60.

Dussán, L. C., Duque, O. H. y González, L. J. (2006) Caracterización tecnológica de caficultores de economía campesina, de los principaples municipios cafeteros de Colombia. CENICAFE, Vol. 57, $\mathrm{N}^{\circ}$ 3, pp. 167-186.

Ejea, M. M. T. (2009) Café y cultura productiva en una región de Veracruz. Nueva Antropología, Vol. 22, $\mathrm{N}^{\circ}$ 7, pp. 33-56.

Gottret, M. V., Junkin, R. e Ilabaca, U.C. (2011) Autoevaluación facilitada para la gestión de empresas asociativas rurales. Turrialba Costa Rica: CATIE.

Guridi, L. y Pérez, De. M. J. C. (2014) La dimensión económica del Desarrollo Humano Local: La economía social y solidaria. Bilbao: Hegoa.

IICA (2009) Estudios de caso en comercialización de pequeños productores rurales. Publicado on line dispoble en: http://legacy.iica.int/Esp/organizacion/LTGC/agroindustria/Documentos Agroindustria Rural/Estudios de caso en comercialización de pequeños productores rurales.pdf (consultado el 04/01/18).

INEGI (2012) Prontuario de información geográfica municipal de los Estados Unidos Mexicanos San Agustín Loxicha, Oaxaca. Publicado on line disponible en: www.inegi.org.mx/sistemas/mexicocifras/datos-geograficos/20/20012.pdf (consultado el 20/ 11/15).

Lele, U. (1981) Co-operatives and the poor: A comparative perspective. World Development, Vol. 9, $\mathrm{N}^{\circ}$ 1, pp. 55-72.

Masera, O., Astier, M. y López-Ridaura, S. (2000) El marco de la Evaluacion MESMIS. In Masera, O., Astier, M. y López-Ridaura, S. (Eds.), Sustentabilidad y Sistemas Campesinos. Cinco experiencias de evaluación en el México rural. México: GIRA AC/Mundi-Prensa/PUMA.

Monzón, C. J. L. y Chaves, Á. R. (2012) La Economía Social en La Unión Europea. Bruselas: Comité Económico y Social Europeo. 
Muñoz, R. M., Aguilar, Á. J., Rendón, M. R. y Altamirano, C. J. R. (2007) Análisis de la dinámica de innovación en cadenas agroalimentarias. México: Universidad Autónoma Chapingo, CIESTAAM/PIIAI.

Muñoz, R. M., Santoyo, C.V. H., y Flores, V. J. J. (2010) Pilares de las organizaciones rurales que perduran. México: Universidad Autónoma Chapingo, CIESTAAM.

Naredo, J. M. (1996) Sobre el origen, el uso y el contenido del término sostenible. Textos sobre Sostenibilidad, Cuadernos de Investigación Urbanística, $\mathrm{N}^{\circ} 41$. Publicado online disponible en http://habitat.aq.upm.es/cs/

Nieto, A. M. y Fernández, G. R. (2004) Responsabilidad social corporativa: la última innovación en management. Universia Bussines Review, $\mathrm{N}^{\circ}$ 1, pp. 28-39.

Olson, M. (1992) La lógica de la acción colectiva. México: Limusa.

Ostrom, E. (2004) Acción colectiva y derechos de propiedad para el desarrollo sostenible: Comprender la acción colectiva. Punto de enfoque II. Resumen 2.

Pérez-Grovas, G. (2000) Evaluación comparada de la sustentabilidad del sistema de manejo de café orgánico en la Unión de Ejidos Majomut, región de los Altos de Chiapas. In Masera, O., Astier, M. y López-Ridaura, S. (Eds.), Sustentabilidad y Sistemas Campesinos. Cinco experiencias de evaluación en el México rural. México: MundiPrensa-GIRA-UNAM, pp. 45-81.

RAINFOREST ALLIANCE (2005) Criterios e indicadores adicionales para la producción de café. Costa Rica.

Ramírez, E., Pino, R., Quiroz, O., Ruiz, R., Sarmiento, L. y Echeverría, J. (2006) Vinculación a mercados dinámicos de territorios rurales pobres y marginados. Fondo Mink'a de Chorlaví.

Remy, S. M. I. y Glave, R. M. (2007) Cafetaleros empresarios. Dinamismo asociativo para el desarrollo en el Perú. Lima, Perú.: Instituto de Estudios Peruanos.

Rodríguez, H. y Ramírez, G. C. J. (2016) Análisis de la sostenibilidad de los procesos de fortalecimiento de la asociatividad rural: El caso de Asomora. Revista de Ciencias Agrícolas, Vol. 33, $\mathrm{N}^{\circ}$ 1, pp. 9-21.

Rondot, P. y Collion, M.-H. (2001) Organizaciones de productores agrícolas. Su contribución al fortalecimiento de las capacidades rurales y reduccion de la pobreza Organizaciones. Banco Mundial. Departamento de Desarrollo Rural.

Rubio, B. (1996) Las organizaciones independientes en México: semblanza de las opciones campesinas ante el proyecto neoliberal. In Carton, G. H (Ed.), Neoliberalismo y organización social en el campo mexicano. México D.F: Plaza y Valdéz Editores, pp.113-163.

Sachs, I. (1981) Ecodesarrollo:concepto, aplicación, beneficios y riesgos. Agricultura y Sociedad, pp. 9-32.

SAGARPA (2011) Plan de innovación de la cafeticultura en el Estado de Oaxaca. México: SAGARPA. pp.131.

SAGARPA-FAO (2006) Proyecto Evaluación Alianza para el Campo 2005: análisis prospectivo de política cafetalera. Mexico D.F: SAGARPA-FAO. pp. 90.

SIAP (2016) Cierre de la producción agrícola. Publicado online disponible en: http://www.siap.gob.mx/cierre-de-la-produccion-agricola-por-estado/ (consultado el 15/01/17).

Todaro, P. M. (2006) Economic Development (9a Ed). Singapur: Longman.

Valdez-Vazquez, I., Sánchez, G. C. del R. y Escalante, A. E. (2017) Proposal for a sustainability evaluation framework for bioenergy production systems using the MESMIS methodology. Renewable and Sustainable Energy Reviews, $\mathrm{N}^{\circ}$ 68, pp.360369. 